\title{
A inteligência analítica em pequenas unidades do Setor de Seguran- ça Pública no Sul de Minas Gerais
}

\author{
Analytical intelligence on small units of the Public Security Sector in South Minas Gerais
}

\author{
Djair Picchiai \\ Doutor em Administração de Empresas \\ Centro Universitário Campo Limpo Paulista \\ djair.picchiai@fgv.br
}

\author{
Alan Rocha \\ Mestre em Administração de Micro e Pequenas Empresas \\ Centro Universitário Campo Limpo Paulista \\ dojux127@gmail.com
}

\begin{abstract}
Resumo
Inteligência analítica tem como objetivo a obtenção, análise e disseminação de conhecimentos sobre fatos e situações que exercem potencial influência sobre o processo decisório. No Brasil o Sistema de Inteligência tem como fundamentos a preservação da soberania nacional, a defesa do Estado Democrático de Direito e a promoção da dignidade da pessoa humana. O presente estudo foi realizado a partir de pesquisa qualitativa e busca por referencial teórico para dar embasamento ao estudo de caso. Foram selecionados os 51 Destacamentos que fazem parte da 17ạ Região da Polícia Militar de Minas Gerais (PMMG). O objetivo foi fazer um levantamento sobre a inteligência analítica (IA) na percepção dos gestores dos destacamentos, que tem um papel fundamental para auxiliar na busca por melhores resultados e auxiliar no planejamento operacional. Sabe-se das dificuldades de utilização da IA neste setor. Como procedimento metodológico, foi utilizado um questionário adaptado de Zarantoneli (2002), o qual foi enviado via correio eletrônico, no qual se buscou verificar a IA como suporte das ações e operações de polícia ostensiva de preservação da ordem pública no estado de Belo Horizonte. De acordo com esta pesquisa pode-se afirmar que a inteligência pode auxiliar na melhoria de resultados. Pode-se constatar que os gestores destas pequenas unidades de Policia Militar, os Destacamentos, mostraram que têm convicção de sua importância, baseando se no resultado da afirmativa de que o serviço de inteligência é relevante do ponto de vista da operacionalidade.
\end{abstract}

\section{Palavras-chave}

Inteligência Analítica. Polícia Militar. Destacamentos. Inteligência no Brasil.

\begin{abstract}
The main objective of intelligence activity is to obtain, analyze and disseminate knowledge about facts and situations that have a potential influence on the decision-making process. In Brazil, the Intelligence System is based on the preservation of national sovereignty, the defense of the Democratic State of Law and the promotion of the dignity of the human person. The present study was carried out based on qualitative research and search for a theoretical framework to support the case study. We selected the 51 detachments that are part of the 17th Region of the Military Police of Minas Gerais (PMMG). The objective was to make a survey about analytical intelligence (Al) in the perception of the managers of the detachments, which has a fundamental role to help in the search for better results and to assist in the operational planning. We know of the difficulties of using $\mathrm{Al}$ in this sector.
\end{abstract}


As a methodological procedure, a questionnaire adapted from Zarantoneli (2002) was used, which was sent via electronic mail, in which it was sought to verify the IA as support for actions and ostensive police operations to preserve public order in the state of Belo Horizonte. According to this research, it can be said that intelligence can help improve results. It can be seen that the managers of these small units of the Military Police, the Detachments, have shown that they are convinced of their importance, based on the result of the affirmation that the intelligence service is relevant from the operative point of view.

\section{Keywords}

Intelligence. Military Police. Detachments. Intelligence in Brazil.

\section{INTRODUÇÃO}

A visão sistêmica de defesa social, no contexto da segurança pública no Estado de Minas Gerais, busca ressaltar a gestão compartilhada das políticas públicas, propondo uma interação com a comunidade, buscando soluções conjuntas para suas necessidades de segurança, por meio da parceria, da coordenação e da transparência das atividades desempenhadas, com o objetivo de conquistar a excelência organizacional da Política Militar de Minas Gerais (PMMG).

Neste sentido, a política pública de Minas Gerais cita que atuação da organização da PMMG, ao buscar atender com eficiência as inúmeras demandas de serviço, precisa que toda a estrutura interna da PMMG funcione e atue de forma coordenada e alinhada aos objetivos institucionais.

Desta forma, a PMMG buscou instituir Destacamentos, que são instituições de polícia e prestadoras de serviços em segurança pública, sendo inseridas em uma corporação estadual, atuando localmente em contextos sociais diferenciados em todos os municípios, principalmente por se tratar de um Estado como o de Minas Gerais, com mais de 853 municípios, correspondendo a 15,3\% dos municípios do país, conforme dados levantados pelo Instituto Brasileiro de Geografia e Estatística (IBGE) no ano de 2011.

Assim, em cada um destes municípios o poder do Estado está representado pela ostensiva preservação da ordem pública oferecida pela instituição, onde está implementado em cada cidade pelo menos uma fração, que representa a menor unidade administrativa da Polícia Militar (PM), as quais possuem até 12 policiais. Vale pontuar ainda que estas pequenas unidades da PMMG constituem um total de mais de $64,83 \%$, onde 553 municípios do total de cidades podem ser atendidos por esta instituição de segurança pública.

A PMMG tem como configuração o ordenamento jurídico, sendo direcionado para atividades preventivas, em sua maioria, com ações repressivas frente à criminalidade, entre elas, está a inteligência analítica (IA), que se constitui como a parte mais visível e importante do enfrentamento diário do crime, por conta de sua acessibilidade. É uma Instituição que tem fomentado discussões quanto às suas características, que envolvem estrutura, formação profissional, competências, atuação, emprego da forca, e, especialmente, uso da atividade de inteligência (BITTNER, 2003).

As possibilidades de se associar a doutrina nacional de IA com a competência da PM são infinitas, considerando que uma das finalidades dessas ações especializadas de inteligência é buscar a prevenção, e neutralizar atos que atentem contra a ordem pública, colocando em prática a missão PM, que é a preservação do estado de harmonia, como um benefício comum a todos (SIEDSCHLAG; CRUZ, 2014). 
O objetivo desse estudo é buscar descrever a gestão dessas pequenas unidades de segurança pública, verificando o grau de maturidade da aplicação da IA no contexto onde estão inseridas, com base na importância da informação, da inteligência na preservação da ordem pública, observando-se o planejamento operacional destas unidades e sua importância na segurança pública, considerando a escassez de recursos, poucos funcionários e peculiaridades sociais das comunidades, sofrendo ainda as interferências do ambiente externo, que exige a necessidade de informações para um desempenho competitivo de uma sociedade cada vez mais exigente.

A pesquisa tem como delimitação a perspectiva de que o uso da IA como ferramenta de análise qualitativa busca trabalhar com a informação do passado, atuando no presente, com a possibilidade de antever atuações no futuro (DAVENPORT; HARRIS; MORISON, 2010).

Existe uma dificuldade em levantar dados que comprovem a utilização da IA, pois é preciso considerar que as pequenas unidades da $\mathrm{PM}$, em sua grande maioria, não atuam de forma corporativa, mas são direcionadas a funcionar de forma local, como entidades independentes em sua atuação operacional, respaldadas em uma atuação rotineira a partir da tomada de decisão do gestor, em virtude de tal situação é que foi construída a pergunta: Como e quando as pequenas unidades de segurança pública usam a IA?

\section{MATERIAL E MÉTODOS}

Para a pesquisa, foi utilizado um questionário adaptado de Zarantoneli (2002), onde se busca verificar a IA como suporte as ações e operações de polícia ostensiva de preservação da ordem pública em Belo Horizonte, porém, o autor teve um enfoque mais na atividade de inteligência da PM em geral, embora o conceito de IA englobe também este tipo de inteligência aplicada na PMMG. Assim, pontua-se que nesse estudo foi utilizada apenas inteligência, considerando a familiaridade dos funcionários com o termo.

A pesquisa foi enviada aos gestores através de correio eletrônico, após levantamento de todos os responsáveis pelas 51 cidades pertencentes a 17ạ região da PMMG, cuja sede é em Pouso Alegre/MG. Do total pesquisado apenas 3 gestores não enviaram suas respostas, não havendo a possibilidade de se precisar quais, pois a pesquisa não obrigava o respondente a se identificar.

O objetivo dessa pesquisa foi verificar a atividade de IA aplicado aos gestores das pequenas unidades da PMMG, ou como são tratados institucionalmente comandantes de Fração, com a finalidade de obter informações sobre a utilização da IA, a fim de se obter dados qualitativos. Registra-se que as afirmativas apuradas referem-se aos tópicos relacionados à Atividade de Inteligência no âmbito dos destacamentos da PM, localizado na 17ạ Região PMMG, como fonte basilar a polícia ostensiva de preservação da ordem pública.

O questionário aplicado é de simples entendimento e resposta imediata, o que foi o bastante para obter dados fundamentais necessários para o entendimento das atividades de Inteligência na instituição militar.

Foi apresentado aos comandantes de frações pesquisadas, questionamento alusivo quanto ao serviço de Inteligência na busca da obtenção de níveis de satisfação do serviço desempenhado, com o objetivo de aferir a importância do serviço para a finalidade precípua da PM.

Buscou-se obter através da pesquisa conhecer mais sobre o universo pesquisado em relação ao serviço de inteligência, e se o mesmo condiz ou não com os anseios da comunidade e sua finalidade ao combate ao crime. Após análise de alguns aspectos relacionados ao 
serviço de inteligência, apresentaram-se aos policiais militares questões ligadas às atividades administrativas da inteligência, política de democratização das informações e o enfoque operacional da atividade, com intuito de observar a necessidade de reformulação deste serviço, do ponto de vista estrutural.

Foram escolhidas 51 cidades do sul de Minas Gerais, as quais fazem parte da 17a região de PM, com sede em Pouso Alegre. As mesmas foram selecionadas por possuírem características peculiares, como população baixa, pequenas unidades da PM com até sete policiais, igualdade de recursos, comunidades com características sociais parecidas, e, ainda, se enquadram em pequenas unidades da PM, que são denominadas Destacamentos de PM, com localidade em uma região com vários municípios onde estão presentes essas pequenas unidades.

\section{SISTEMAS DE INFORMAÇÃO (SI)}

A teoria geral dos sistemas escrita pelo biólogo Bertalanffy tinha como evidência sua descrença em uma visão meramente mecanicista, o que o levava a acreditar em fenômenos biológicos, os quais deveriam ser ampliados por uma visão que considerasse o todo, assim como as suas inter-relações com o seu ambiente.

Bertalanffy (1986) apontava ainda que essa teoria poderia ser definida como sendo uma ciência geral de 'totalidade', elaborada a partir de uma disciplina matemática puramente formal em si mesma, mas aplicável às várias ciências empíricas.

Assim, a fim de efetuar uma tentativa de sintetizar o pensamento com vista aos propósitos, a Teoria Geral dos Sistemas pode ser assim explicitada: há uma tendência geral à integração das várias ciências naturais e sociais e está integração gira em torno de uma teoria geral dos sistemas; esta teoria poderá ter um recurso importante ao buscar uma teoria exata em campos não físicos da ciência; ao elaborar princípios unificadores que correm verticalmente pelo universo das ciências, esta teoria nos remeterá à meta da unificação da ciência; isto poderá conduzir a uma integração, de cuja ausência a investigação científica em muito se ressente; um sistema pode ser definido como um conjunto de elementos em interrelação entre si e com o ambiente.

Para Davenport (1998) e Choo (2006), as informações têm o ser humano como agente principal de manipulação. Kumar (1997) realiza uma abordagem da informação sob a ótica tecnológica sendo a informática o agente modificador. As pessoas devem ser os principais agentes, porém, a tecnologia deve ser disponibilizada para facilitar as atividades organizacionais, e os sistemas de informações podem ser o mecanismo mais apropriado para integrar pessoas, tecnologias e informação.

No SI os dados são transformados e organizados, podendo envolver elementos como recursos tecnológicos e computacionais para a geração da informação, fundamentada nos componentes de hardware, seus periféricos, software e seus recursos (LAUDON; LAUDON, 2007).

Vale pontuar ainda que o SI pode ser definido como um conjunto de componentes inter-relacionados usados para coletar, processar, armazenar e distribuir informações, através de três atividades principais, como entrada de dados, processamento e saída, relatórios, análises e realimentação (O'BRIEN, 2004; LAUDON; LAUDON, 2007).

Conforme O'Brien (2004), um sistema possui três funções básicas: a entrada, que é o momento de coletar o que vai ser trabalhado; o processamento, que é a transformação do que foi coletado; e a saída, que é o momento que deve ser distribuído ao usuário. 


\section{INTELIGÊNCIA ANALÍTICA (IA)}

A IA confere às empresas a capacidade de acumular informações, adquirir conhecimentos sobre clientes, concorrentes e operações internas, assim como proporcionar a mudança de comportamentos em relação à tomada de decisão para alcançar maior lucratividade e outras metas corporativas (LAUDON; LAUDON, 2007).

Os mesmos autores destacam que, por meio de bancos de dados das organizações, podem-se monitorar as transações, os gerentes podem usar ferramentas de IA para encontrar sentidos e padrões, analisando e tomando decisões bem fundamentadas, auxiliados por ferramentas e tecnologias de IA.

Como um termo geral, o termo analítico refere-se à ciência da análise lógica, como citam Liberatore e Luo (2010). Para Davenport e Harris (2007), o termo IA pode ser apontado como uso extensivo de dados, análise estatística e quantitativa, modelos preditivos e gestão baseada em fatos, que auxiliem na tomada de decisão e ações de uma organização.

A IA pode ser considerada uma prática na melhoria do desempenho em domínios fundamentais do negócio, pois tem como objetivo abandonar a intuição na tomada de decisões, e passa se basear em fatos. Decisões importantes precisam ser pensadas, levando em consideração o bem-estar de uma vida humana, o bem-estar social, o convívio em uma comunidade, além de estar amparada em dados e informações que trabalhadas auxiliam na melhoria dos resultados, pois este é o uso que deveria ser empregado também na segurança pública, pensando na preservação da ordem pública (DAVENPORT; HARRIS; MORISON, 2010).

Quando uma organização passa a usar a IA, é possível executar métodos analíticos ou técnicas lógicas, com o intuito de transformar dados em ações por meio de análises e compreensão do contexto, voltados para decisão e resolução de problemas. É um processo que pode ser iniciado pelo desejo de responder a um problema específico ou a necessidade de explorar e aprender a partir de uma base de dados (LIBERATORE; LUO, 2010).

Segundo pesquisa de Thompson (2004 apud TURBAM et al. 2009), os maiores benefícios da IA são:

a) geração de relatórios mais rápida e precisa (81\%)

b) melhor tomada de decisões (78\%)

c) melhor serviço ao cliente (56\%)

d) maior receita $(49 \%)$

Para Turbam et al. (2009), o que se percebe é que cada vez mais existem evidencias de que as iniciativas de IA se tornam uma obrigação estratégica, apontando que muitas organizações acabam tendo uma vantagem estratégica quando entendem sua importância.

A partir do advento da informatização é muito comum se deparar com sistemas que fazem uso da inteligência analítica, o que se faz presente na maioria das organizações. $A$ informatização de dados é algo constante e comum nas empresas; informações essas que antes não existiam passaram a ficar totalmente disponíveis. Diante disso, uma das grandes preocupações é a maneira e a forma como esses dados poderiam ser usados em prol do sucesso dos negócios, e ainda, uma melhor maneira de analisar os dados que foram gerados com essa informatização. As organizações precisam saber utilizar esses dados, visando um incremento no sucesso do negócio, fazendo com que as informações maximizem os resultados corporativos, o que descreve bem o que é inteligência analítica (O'BRIEN, 2004).

Davenport e Harris (2007) apontam dois principais e essenciais componentes para cultivar a IA: tecnologia, que diz respeito aos recursos representados por tecnologias, pelos dados e como eles podem ser combinados em uma arquitetura analítica geral, o que hoje 
em dia é tecnicamente viável, sendo possível coletar e armazenar enormes quantidades de dados, e uma arquitetura de business intelligence que permite a organização desses dados, juntamente com o uso de outras ferramentas; e pessoas, que se mostra tão ou o mais importante que a tecnologia, porém, não é muito abordado. Diante disso, é preciso considerar que os aspectos humanos e organizacionais da liderança analítica são elementos considerados diferenciadores e essenciais.

Para Leme (2004), a IA contém algumas características principais, como a extração e integração de dados de múltiplos bancos de dados, levando ao uso da experiência para a democratização do capital intelectual, onde as informações contextualizadas devem ser analisadas em um nível de totalização e agrupamento maior, ajudando ainda na identificação de relações de causa e efeito, o que facilita o desenho de cenários, na criação de simulações e no estudo de tendências de mercado.

Existem vários campos de atuação em que as técnicas de análise podem ser usadas. Por exemplo, pode-se utilizar a IA para projetar ou simular comportamentos do tráfego nas grandes metrópoles, mercado de ações, gestão de finanças, gestão de RH, gestão de custo. São várias as possibilidades de utilização deste recurso, desde que se tenham os dados disponíveis numa base sólida e confiável. Esse modelo é constituído com base em premissas da exploração, e aprimorado com frequência para que venha se tornar cada vez mais inteligente e eficaz, assim, quanto maior o seu histórico de dados armazenados no banco, maior será a exatidão da consulta.

Segundo Pereira (2009), no Brasil o termo IA passou a ser usado no lugar de informações, a partir do ano de 1990, por ocasião da extinção do Serviço Nacional de Informações (SNI). O objetivo da mudança de nomenclatura foi de tentar dissociar da atividade a imagem de repressão e violação aos direitos civis. Ocorridas durante os anos em que o SNI atuou a serviço da ditadura militar.

Segundo Turban et al. (2009), a IA é um termo abrangente, que pode incluir arquiteturas, ferramentas, bancos de dados, aplicações e metodologias, podendo ser uma expressão livre de conteúdo, por significar coisas diferentes para pessoas diferentes. A IA se mostra importante numa empresa, pois possibilita o fornecimento de informações precisas quando necessário, sendo importantes para todo o tipo de decisão, assim como para o planejamento estratégico e a sobrevivência da empresa.

A IA auxilia no fornecimento de informações precisas, detalhadas e oportunas, auxiliando ainda na identificação de oportunidades de negócios, aumentando a fidelidade dos parceiros, eliminando, na maioria das vezes, problemas operacionais diversos (TURBAN et al., 2009).

\section{RESULTADOS DA PESQUISA}

\subsection{Verificação da satisfação do serviço de inteligência}

Como demonstrado, no Gráfico 1, que se refere à afirmação - O serviço de inteligência é satisfatório - constata a realidade do que o gestor recebe do conhecimento produzido pelo órgão de inteligência de sua unidade -, os dados mostram que $42 \%$ concordam parcialmente que o serviço de inteligência é satisfatório, outros $24 \%$ consideram o serviço de inteligência satisfatório, $16 \%$ discordam totalmente, $13 \%$ discordam parcialmente e $5 \%$ se mostram indiferentes com a questão apontada na pesquisa. 
Gráfico 1 - Satisfação com relação ao serviço de inteligência

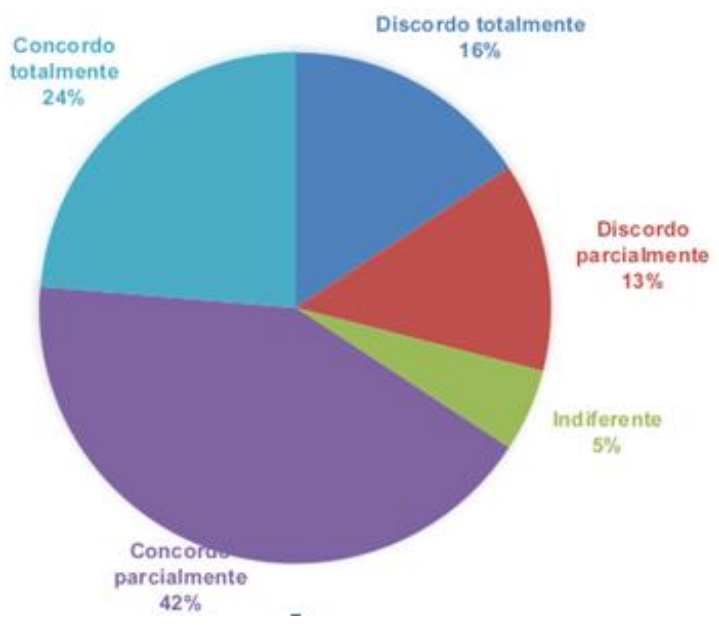

Fonte: dados da pesquisa (2017).

Contudo, é necessário ponderar em relação ao resultado apresentado, pois retrata a importância da inteligência na aplicação de recursos e auxílio na preservação da ordem pública, mas ainda, é preciso elaborar uma avaliação para buscar mudanças e elevar o nível de satisfação a um patamar mais alto, já que os destacamentos e seus gestores necessitam de informações ou conhecimento para eficiência na tomada de decisão, conforme trata Choo (2006), em relação à produção do conhecimento e sua finalidade, onde afirma que a informação é um componente intrínseco de tudo o que uma organização faz, e, não havendo uma clara compreensão dos processos organizacionais e humanos, as instituições não são capazes de perceber a importância dos dados levantados e a riqueza das fontes existentes.

Percebe-se que dentre os respondentes há um afastamento quanto à satisfação percebida do uso da IA, o que deveria ser verificado, pois eles podem estar trabalhando empiricamente com os dados disponíveis, não sendo otimizados para uma maior efetividade na tomada de decisões. Pelo menos $16 \%$ não estão satisfeitos, a IA não esta atingindo seus objetivos junto a estas unidades.

Gráfico 2 - Relevância do ponto de vista da operacionalidade

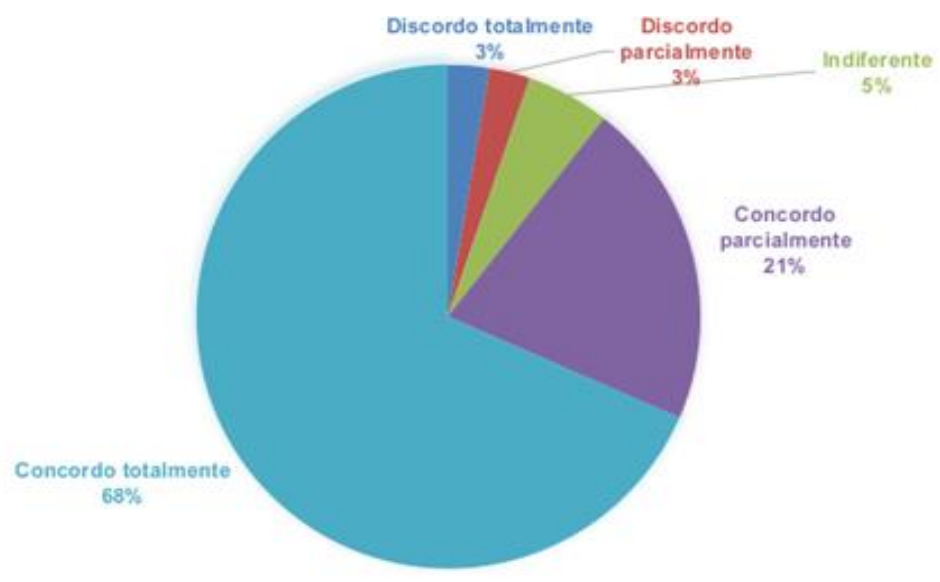

Fonte: dados da pesquisa (2017). 
Essa importância também é percebida no Gráfico 2, de acordo com a afirmativa - 0 serviço de inteligência é relevante do ponto de vista da operacionalidade -, onde $68 \%$ dos respondentes consideram o serviço de inteligência totalmente relevante, e $21 \%$ parcialmente relevante, num total de $89 \%$, dos quais pode se considerar o resultado positivo sob a ótica de relevância, em que $5 \%$ são indiferentes, 3\% discordam parcialmente e $3 \%$ discordam totalmente, uma vez que, nos destacamentos, o serviço policial militar é em sua maioria empregado na preservação ostensiva da ordem pública, no combate criminal, no contato comunitário, ou seja, diretamente nas ruas. É onde o gestor entende que é importante a informação possibilitar o suporte ao serviço que deve prestar, já que a inteligência analítica utiliza dados, análise estatística e quantitativa, modelos preditivos e gestão baseada em fatos que auxiliam na tomada de decisão e nas ações de uma organização.

Observa-se que para os gestores a IA é importante, assume um papel fundamental, principalmente do ponto de vista operacional, seja na alocação de recursos, analise dos dados, atendimento diferenciado ao cliente, destacando-se sobremaneira como mostram os dados da pesquisa.

\subsection{Importância da inteligência sob o enfoque operacional nos Destacamentos}

Como em qualquer outra organização, se espera que a PMMG possa melhorar sua qualidade na prestação de serviços, através de apoio no serviço operacional de informações que possam auxiliar no ambiente de atuação da polícia militar. A Inteligência, por sua vez, é um produto de valor agregado decorrente do trato dos dados obtidos, potencialmente significativo para a tomada de decisões. Numa visão mais ampla, podemos dizer que é uma estrutura, um processo e um produto.

Neste quesito, buscaram-se evidências, segundo a percepção dos comandantes dos destacamentos, em que os mesmos percebem a importância da inteligência, como uma ferramenta que busca propiciar um melhor aproveitamento das informações de segurança pública. Levando a uma segmentação das atividades policiais direcionadas para os "pontos quentes" e "tempos críticos", porém, exige o discernimento necessário para encontrar o caminho para aqueles que tomam as decisões e levá-los a compreender e responder adequadamente às informações.

Os percentuais da pesquisa referentes à afirmação - Quanto ao enfoque operacional das atividades de inteligência, consideram que o campo de Defesa Pública deveria ser prioritário para a inteligência - demonstram a importância da inteligência quanto à defesa pública para os gestores, os percentuais que se resumem em um conjunto de ações preventivas, tais como a defesa do cidadão, da comunidade, pois $50 \%$ concordam totalmente e $42 \%$ concordam parcialmente e apenas $8 \%$ discordam parcialmente, conforme demonstra o Gráfico 3.

A maior parte do universo pesquisado, ou seja, 92\% concorda total ou parcialmente que a defesa pública deve ser a prioridade da inteligência, devendo ser aplicados a maior parte dos recursos informacionais com o objetivo de defender a sociedade, pois é uma prática que possibilita melhora no desempenho em domínios fundamentais do negócio, uma vez que é baseada em fatos, e decisões como essas devem considerar o bem estar de uma vida humana, bem estar social e o convívio em uma comunidade.

Com o uso da IA como ferramenta de melhoria no tratamento dos dados, produção de informações poderá se alcançar melhores resultados, havendo um consequente aumento do desempenho operacional positivo na preservação da ordem pública, que constitucional- 
mente é função precípua da PMMG e não seria diferente nos destacamentos, e como se vê a defesa pública seria um dos principais focos a se trabalhar.

Gráfico 3 - Defesa Pública como prioridade para a inteligência

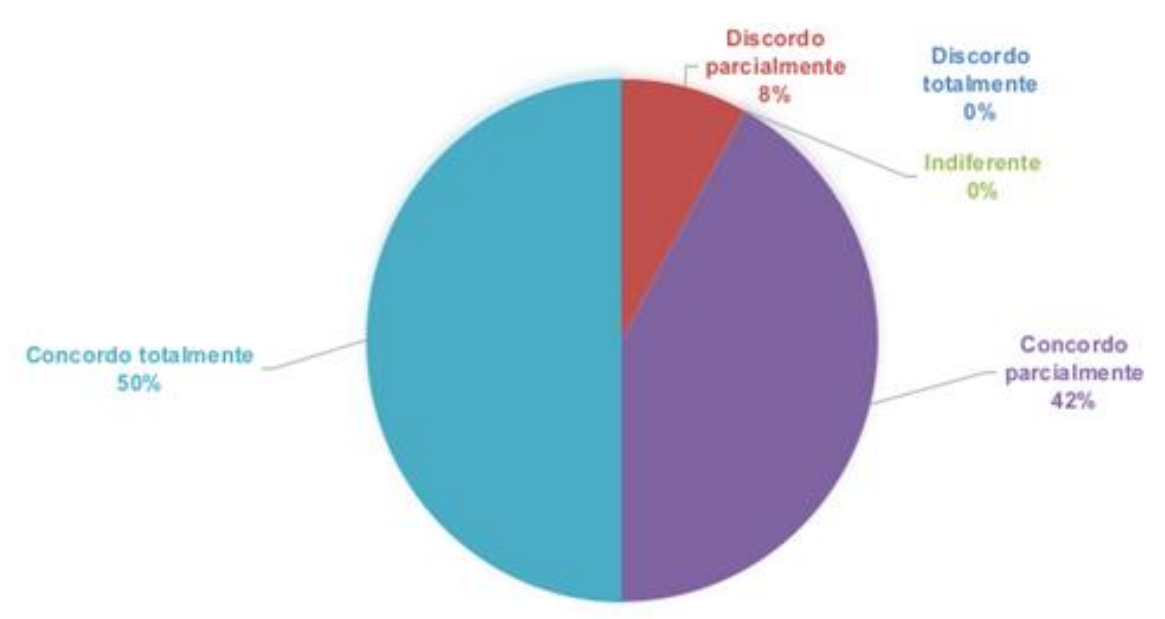

Fonte: dados da pesquisa (2017)

No Gráfico 4, levando-se em conta a assertiva - Quanto ao enfoque operacional das atividades de inteligência, há o acompanhamento da aplicação do Geoprocessamento em seu Destacamento -, fica evidenciado que $16 \%$ são indiferentes e $16 \%$ discordam totalmente, somando $32 \%$, o que caracteriza a falta do uso desta ferramenta por uma grande parte dos respondentes, seja pelo desconhecimento ou por falta de motivação para a aplicação.

E ainda, verifica-se que $26 \%$ concordam totalmente, $26 \%$ concordam parcialmente e $16 \%$ discordam parcialmente. Deste total, apenas $26 \%$ usam uma ferramenta de geoprocessamento como apoio na utilização da informação para planejamento do emprego operacional. Há que se ressaltar que a disposição geográfica pode ser importante na compreensão espacial da atividade criminal em uma determinada área de atuação, levando a um entendimento visual e geográfico dos índices criminais, o que pode auxiliar em um dos pontos principais na busca do conhecimento de uma atividade. A compreensão espacial da atividade criminal possibilita o planejamento com objetividade, eficiência e eficácia.

Gráfico 4 - Aplicação do Geoprocessamento no Destacamento

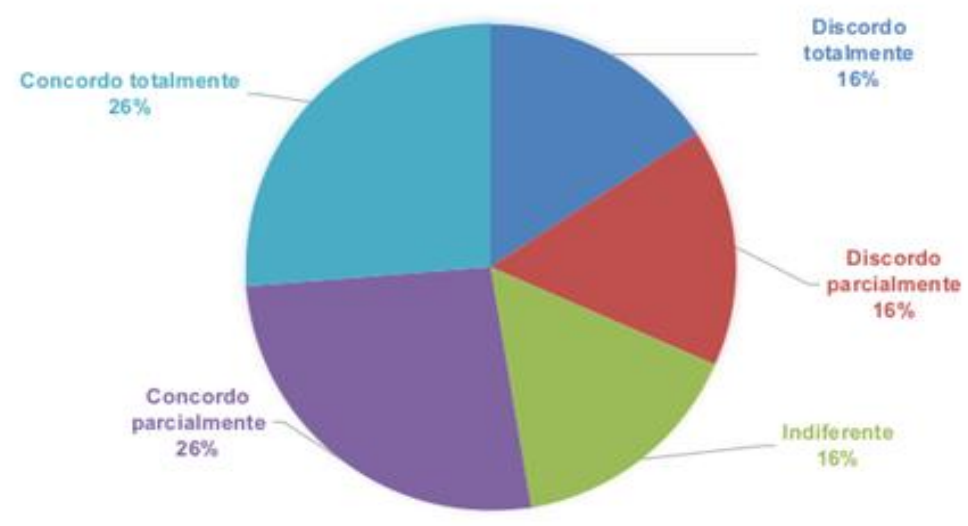

Fonte: dados da pesquisa (2017). 
Como ferramenta, a IA deve auxiliar os gestores e melhorar resultados; em se falando do uso de tecnologia como aporte principal desta, o geoprocessamento, possibilitando dimensionamento geográfico dos dados e resultados do trabalho policial, pode trazer uma melhor eficiência e eficácia no uso de recursos humanos e logísticos, produção de conhecimento, uso de informações com maior efetividade, mas se percebe um distanciamento deste uso nos destacamentos pesquisados.

A assertiva - Quanto ao enfoque operacional das atividades de inteligência, faz-se necessária uma maior aproximação dos elementos da atividade de inteligência àqueles empenhados nas atividades de polícia ostensiva, visando à prevenção criminal - diz respeito à opinião dos respondentes sobre uma aproximação do profissional de inteligência, alocado no nível tático, nas unidades ou batalhões, junto aos profissionais empenhados na atividade de polícia ostensiva, que executam a atividade policial nas ruas, onde o serviço operacional é fundamental para que se atendam as suas expectativas.

A pesquisa aponta que $79 \%$ concordam totalmente com a afirmativa, $13 \%$ concordam parcialmente e discordam parcialmente apenas $8 \%$. De maneira geral, cerca de $92 \%$ dos concordantes percebem que há a necessidade de aproximação das atividades, sendo que o distanciamento entre as duas pode trazer prejuízos à atividade policial e até mesmo prejudicar o desempenho da PM também nas pequenas unidades, onde os gestores sentem que é muito importante a aproximação de quem trabalha diretamente com a inteligência.

A IA deve possibilitar o fornecimento de informações precisas quando necessário, sendo importante para todo tipo de decisão, assim como para o planejamento estratégico, a gestão das equipes para esta interação pode interferir no resultado do que se espera da IA, pois pode gerar um afastamento dos gestores em relação ao profissional de inteligência, consequentemente interferindo na aplicação ou no uso da informação.

O Gráfico 5, conforme a assertiva - Quanto ao enfoque operacional das atividades de inteligência, o policiamento velado como suporte da atividade ostensiva deve executar os levantamentos de informações da criminalidade, não se confundindo com investigação criminal que é atinente à Polícia Civil -, mostra que $76 \%$ concordam totalmente com a necessidade de suporte do policial velado para auxiliar na execução da atividade ostensiva e $16 \%$ concordam parcialmente, e ainda, 3\% discordam parcialmente, 3\% indiferentes, $2 \%$ discordam totalmente.

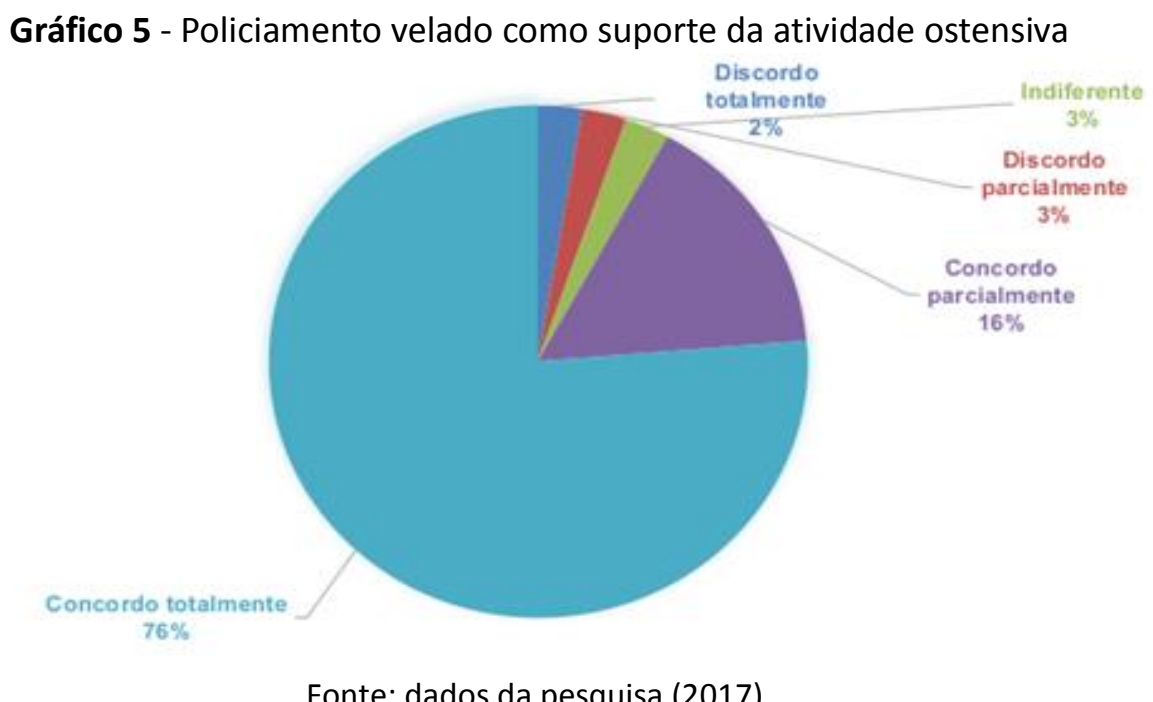


Nesse sentido, fica evidenciada a importância deste serviço para o gestor do Destacamento, uma vez que a maioria considera sua utilização relevante para o levantamento de informações, as quais poderão dar suporte à tomada de decisão, nas ações do policiamento ostensivo, como mostra o Gráfico 5. Porém, como instituição pública o empenho de recursos humanos necessários depende de conscientização de escalão superior e governamental para uma efetiva aplicação.

A Constituição Federal traz em seu art. 144, § 5ㅇ “Às polícias militares cabem a polícia ostensiva e a preservação da ordem pública." Segundo os preceitos constitucionais, a função típica da polícia militar é ser ostensiva e buscar a preservação da ordem pública, ainda assim, verifica-se que os gestores dos destacamentos entendem que um serviço velado, ou seja, com policiais sem o uso da farda, poderia auxiliar na busca de informações da criminalidade, não se confundido com investigação criminal, que é função precípua da Polícia Civil.

Em relação a IA o policiamento velado seria a aplicação operacional das informações trabalhadas, dos conhecimentos produzidos, com a finalidade de se melhorar a resposta ao cliente que é a comunidade de uma maneira geral, um recurso que aliado a IA poderia atingir excelentes resultados.

\subsection{Utilização da IA nas pequenas Unidades da Segurança Pública}

O objetivo desse item é verificar o desenvolvimento das atividades administrativas no processo de manipulação, tratamento e análise de dados, os métodos utilizados na ampliação de conhecimento e informações que afetam as pequenas unidades de segurança pública. Foram formuladas questões em relação ao insumo principal a produção de informações e ferramentas que propiciem apoio ao sistema de tomada de decisão do gestor.

Os administradores tomam decisões diversas em face de problemas e oportunidades que se apresentam às organizações e a qualidade dessas decisões é que vai determinar o seu desempenho. Especialmente, no caso da PMMG, a natureza dos problemas que envolvem o tomador de decisões faz com que determinadas deliberações possam ensejar prejuízos a vários indivíduos e, nos casos mais complexos, determinar a possibilidade de vida ou de morte de uma ou mais pessoas.

Gráfico 6 - Falta ferramentas de apoio à tomada de decisão

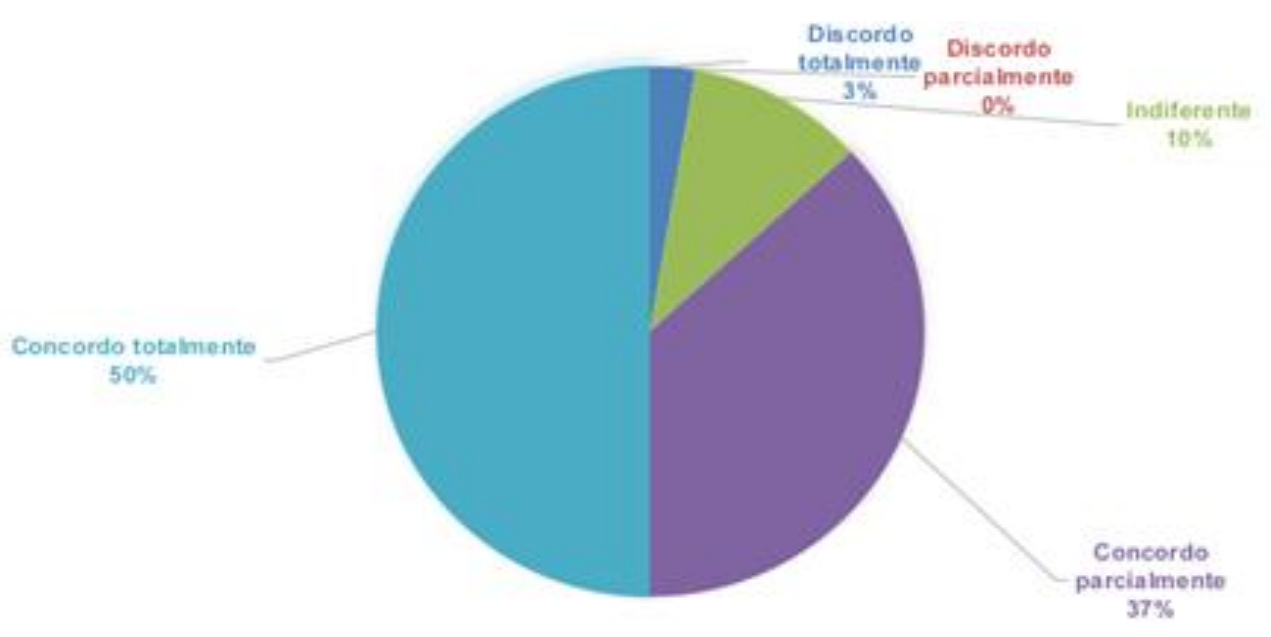

Fonte: dados da pesquisa (2017). 
No Gráfico 6, foi abordada a assertiva - Quanto ao foco das atividades administrativas da atividade de inteligência, falta ferramentas que deem maior apoio à tomada de decisão no planejamento operacional - em que $50 \%$ concordando totalmente, $37 \%$ concordando parcialmente, $10 \%$ indiferentes e $3 \%$ discordando totalmente, o que denota um nível de importância considerável quanto ao assunto, pois $87 \%$ concordam que falta de ferramentas de apoio à tomada de decisão.

Essa decisão tomada rotineiramente pelos gestores nos destacamentos, de acordo com o resultado, em sua maioria, então assumem um papel empírico, aleatório e não científico, que pode trazer prejuízos à organização. Evidencia-se aqui que a IA poderia ser aplicada de maneira mais eficaz, pois um de seus objetivos que é auxiliar na tomada de decisão pode estar sendo relegado pela instituição.

No Gráfico 7, que se refere à assertiva - Quanto ao foco das atividades administrativas da atividade de inteligência, torna-se necessário um órgão de inteligência bem estruturado e voltado para a prevenção da criminalidade -, os resultados demonstraram que $79 \%$ concordam totalmente, $13 \%$ concordam parcialmente, $5 \%$ indiferentes, $3 \%$ indiferentes e nenhum dos respondentes discordaram totalmente com importância da inteligência.

Gráfico 7 - Inteligência estruturada e voltada para prevenção da criminalidade

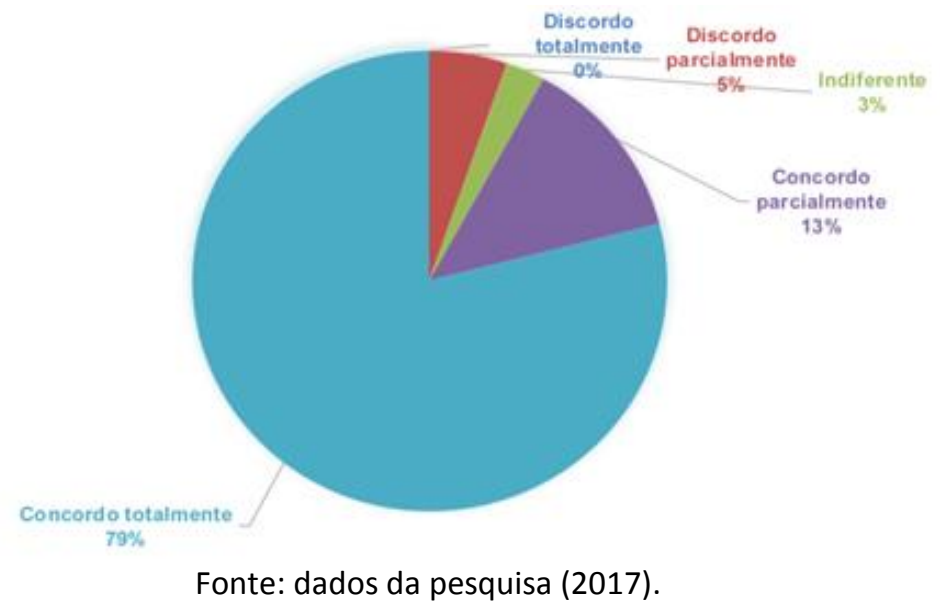

A própria DNISP, cujo prefácio do documento elaborado em 2007 que não recebeu classificação sigilosa, traz a preocupação na busca da integração entre os órgãos de inteligência em prol de um controle eficiente da criminalidade, em que se destacam as medidas de direção central, coordenação, controle e produção de conhecimento, todas elas integradas em níveis local, estadual, regional.

Mas conforme observamos, $92 \%$ dos concordantes sentem a necessidade de um órgão estruturado que lhes deem apoio em sua atividade, o que significa que sentem deficiência na estrutura atual de inteligência que não chega até o destacamento, e cujo objetivo deveria estar em uma só sintonia com vista ao combate à criminalidade. Há a necessidade de uma estruturação da IA voltada ao combate criminal, na percepção dos gestores, que pode não estar ocorrendo ou estes não percebem a utilização deste recurso sob este aspecto.

Como se verifica no Gráfico 8, com base na assertiva - Quanto ao foco das atividades administrativas da atividade de inteligência, o destacamento sente a necessidade de que o serviço de inteligência efetue análise qualitativa de incidência de criminalidade, sobre os relatórios de eventos de defesa social como, por exemplo, verificação do perfil do agressor e suas vítimas, a ligação do criminoso com outros marginais, constância nas zonas e horários 
de crime, bem como em outros documentos indicadores de Segurança Pública -, 50\% concordam totalmente, $34 \%$ concordam parcialmente, $10 \%$ indiferentes, $3 \%$ concordam parcialmente e $3 \%$ discordam totalmente.

Os dados mostram ainda que $92 \%$ concordam com a necessidade de uma análise qualitativa da incidência criminal, o que pode não chegar aos destacamentos ou pode não estar sendo produzido para fornecer apoio informacional.

Gráfico 8 - Necessidade de análise qualitativa de incidência de criminalidade

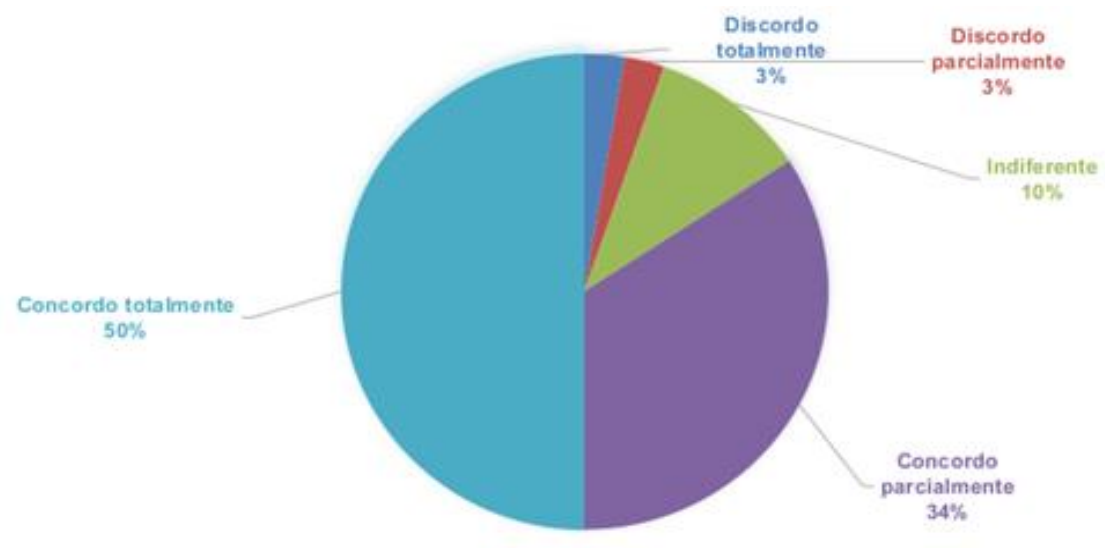

Fonte: dados da pesquisa (2017).

A inteligência da PMMG tem por escopo executar a atividade de inteligência no âmbito da PMMG, não variando muito em relação às atribuições das demais agências de inteligência de outros órgãos que, num aspecto geral, diz respeito à obtenção e análise de informações que venham a subsidiar o processo decisório de diferentes níveis e atividades, diretamente relacionado com o conceito do que a IA se propõe, porém, os gestores veem como uma necessidade a se suprir, o resultado seria uma melhoria na prestação do serviço à população.

Para que haja uma efetiva integração de ações e uma maior efetividade na utilização do produto da IA, é necessário acompanhamento do policiamento no âmbito operacional e de estrutura organizacional, analise qualitativa dos dados, suporte à tomada de decisão para os gestores.

Vislumbra se, então, o policiamento orientado pela IA como uma alternativa capaz de possibilitar esse salto evolutivo. E, como citado, em todo o Estado a grande maioria é destacamentos e também podem estar sentindo a necessidade de informações e conhecimento para desempenhar melhor suas atividades, conseguir melhores resultados.

\section{DISCUSSÃO DOS RESULTADOS}

A IA pode resultar numa melhoria do desempenho, evitando que os envolvidos usem somente intuição em tomada de decisões. Atualmente, a atividade criminosa passou a ser informada e organizada de forma equivalente à atividade policial. Portanto, nesse cenário, a inteligência é a ferramenta indicada para atuar preventivamente, coletando os dados no seio da própria organização criminosa.

A inteligência pode auxiliar na melhoria de resultados, fato comprovado na pesquisa, em que os gestores destas pequenas unidades de PM, os Destacamentos, demostraram ter 
conviç̧ão de sua importância. Quando questionados sobre a operacionalidade, $89 \%$ dos entrevistados demonstraram concordar que é benéfica. Além disto, verificou-se que $76 \%$ dos gestores, em seu ponto de vista, consideram que o serviço de inteligência da PMMG precisa de uma reformulação. A atividade de inteligência, em relação ao seu enfoque operacional, foi apontando por $92 \%$ dos gestores, como um importante instrumento de defesa pública, ou seja, a defesa da sociedade, do combate ao crime, do cidadão. Por isso, a inteligência nos Destacamentos pode alcançar resultados positivos, já que constitucionalmente a PMMG é a força de preservação da ordem pública.

Vale pontuar ainda que das 51 cidades pesquisadas, aproximadamente $92 \%$ buscam essa aproximação dos serviços em relação à inteligência, principalmente, visando à prevenção criminal. Quanto à democratização das informações, a necessidade de contato destacase dentre $97 \%$ dos concordantes, além da necessidade por interação com $95 \%$ dos concordantes, o que leva a um importante questionamento: por que não o fazer?

O sistema de informação tem como propósito melhorar o acesso às informações, o que propicia uma facilidade em fazer relatórios mais precisos e rápidos, com menor preço, além de adotar procedimentos capazes de garantir a realização dos objetivos, de maneira direta, simples e eficiente para qualquer organização. Enfatiza-se, ainda, que a saída do sistema de informação, isto é, seus relatórios ou a qualidade do serviço, é a principal informação fornecida pela organização e a mesma deve ser de qualidade, precisa, objetiva, visando atender aos anseios do gestor responsável pelo planejamento do emprego dos recursos disponíveis.

Com relação ao enfoque operacional, é importante destacar alguns pontos, apontando que os comandantes de Destacamentos demonstram que consideram muito importante o acompanhamento de marginais, por meio de banco de dados de presos e cidadãos infratores, composto por fotografias, dados criminais, evolução do processo criminal, onde $97 \%$ dos entrevistados noção dessa importância, e ainda, $21 \%$ discordam e outros $8 \%$ se mostram indiferentes, pois não há ferramentas disponíveis para fornecer tais informações.

O planejamento de todo o serviço demanda o trabalho sobre os dados e a transformação em informação, o que pode estar faltando aos gestores, conforme mostrou à pesquisa na assertiva que aponta a falta de ferramentas que possibilitem um maior apoio à tomada de decisão no planejamento operacional, em que $87 \%$ dos concordantes sentem falta desse apoio e $95 \%$ dos concordantes o consideram de vital importância. Além disso, $97 \%$ reconhecem que as ferramentas tecnológicas são importantes na disseminação dessas informações.

Outro ponto importante é o enfoque administrativo, no qual os comandantes dos Destacamentos demonstraram necessidade de uma inteligência estruturada que auxilie na criminalidade, com $92 \%$ dos concordantes, o que ainda é ratificado por $91 \%$ dos concordantes que demonstraram necessidade de uma análise qualitativa de incidência criminal, evidenciando, mais uma vez, a indisponibilidade destas informações. Um ponto importante apurado diz respeito ao retrabalho nos Destacamentos, onde $92 \%$ concordaram, evidenciando que é um gasto desnecessário de tempo, mão de obra, recursos e consequentemente do dinheiro público.

A maior parte do universo pesquisado, ou seja, 92\% concordam total ou parcialmente que a defesa pública deve ser a prioridade da inteligência, na defesa pública devem ser aplicados a maior parte dos recursos informacionais com o objetivo de defender a sociedade. Como resultado haverá um aumento do desempenho operacional positivo na preservação da ordem pública, que constitucionalmente é função precípua da PMMG e não seria diferente nos destacamentos. 


\section{CONSIDERAÇÕES FINAIS}

A integração com os policiais diretamente empregados da atividade de preservação da ordem pública, em contato direto com os clientes da segurança pública, pode contribuir com geração de conhecimento onde em vários níveis os tomadores de decisões terão informações diretas do ambiente onde o serviço é prestado, levando a uma melhoria de prestação do serviço, da qualidade deste, através da análise e discussão de pontos relevantes em ambos os lados.

É importante considerar que o SI pode ser definido como um conjunto de componentes inter-relacionados usados para coletar, processar, armazenar e distribuir informações, através de três atividades principais, como entrada de dados, processamento e saída, relatórios, análises e realimentação (O'BRIEN, 2004; LAUDON; LAUDON, 2007). Além disso, outros órgãos de inteligência integram o todo, quando temos como clientes a mesma sociedade. Mesmo que de fontes diferentes, a informação e o conhecimento compartilhados estão direcionados ao mesmo objetivo, que é a preservação da ordem pública.

Apesar de a maioria concordar com essa integração externa, o contato com outros órgãos de inteligência precisa obedecer a uma rotina burocrática interna, onde se percebe que a informação seria importante. Estabelecer uma rotina visando esta integração de modo que os gestores dos destacamentos possam se beneficiar de informações oriundas de outras fontes de inteligência, entre as quais se destaca a polícia civil, que também atua rotineiramente nos municípios mineiros com uma estrutura própria, pode beneficiar ambos os lados.

A relevância dos pequenos municípios do estado de MG fica evidente quando verificamos os números, posto que são 666 de 853 cidades, ou seja, 78\% são pequenos, conforme a estimativa populacional referida pelo IBGE, em 2016. Em todos eles, há pelo menos um Destacamento da PMMG, cada um com suas peculiaridades regionais, mas agindo como o único órgão de segurança pública, sempre presente e buscando preservar a ordem pública.

Com relação aos municípios menores, se houvesse controle e aplicação da IA de maneira mais efetiva, a percepção da sensação de segurança no Estado se faria mais evidencia$\mathrm{da}$, pois, apesar de ser a maioria que busca o empenho de recursos a serem aplicados, estes são muito menores em comparação com as grandes cidades, principalmente, em relação ao número de policiais para se conseguir manter a segurança pública, em um território bem menor, com uma população menor, mas demonstrando uma representatividade muito maior no Estado.

Isso não ocorre apenas em Minas Gerais, mas em vários Estados com as mesmas características, onde a implementação de recursos poderia alcançar melhores resultados do que em municípios maiores com um custo bem menor, com uma mudança de postura. $A$ instituição como um todo deve atentar para a construção de um sistema de informações para apoio também aos Destacamentos e uma aproximação, considerando que a maioria busca e anseia por isto, o que pode levar a melhores resultados.

Não há como definir a maturidade da instituição com relação a IA, como um todo, porém, com base na amostra, percebe-se que os gestores têm a percepção do conceito, reconhecem a importância, mas há a necessidade de se trabalhar melhor essa ferramenta, cujos objetivos podem influenciar na melhoria dos resultados.

\section{REFERÊNCIAS}

BERTALANFFY, L. V. General Systems Theory. New York: Braziller, 1986. 
BITTNER, E. Aspectos do trabalho policial. Trad. Ana Luísa Amêndola Pinheiro. São Paulo: Editora da Universidade de São Paulo, 2003.

BRASIL. Presidência da República. Constituição da República Federativa do Brasil de 1988. Brasília, DF, 1988. Disponível em:

http://www.planalto.gov.br/ccivil 03/constituicao/constituicao.htm. Acesso em: Acesso em: 6 jul. 2018.

BRASIL. Portaria no 22, de 22 de julho de 2009. Aprova a Doutrina Nacional de Inteligência de Segurança Pública - DNISP, em conformidade com o disposto no art. 3o do Decreto no 3.695, de 21 de dezembro de 2000. Brasília, DF, 2009.

CERVO, A. L.; BERVIAN, P.A. Metodologia científica: para uso dos estudantes universitários. 3. ed. São Paulo: McGraw-Hill, 1983.

CHOO, C. W. A organização do conhecimento: como as organizações usam a informação para criar significado, construir conhecimento e tomar decisões. 2. ed. São Paulo: Editora Senac São Paulo, 2006.

DAVENPORT, T. H. Ecologia da informação: por que só a tecnologia não basta para o sucesso na era da informação. São Paulo: Futura, 1998.

DAVENPORT, T. H.; HARRIS, J. G. Competing on Analytics: the new science of winning. Hardcover: Harvard Business Review Press, 2007.

DAVENPORT, T. H.; HARRIS, J. G.; MORISON, R. IA nos negócios: como usar a análise de informações para obter resultados superiores. Tradução: Ana Beatriz Rodrigues. Rio de Janeiro: Elsiever, 2010.

INSTITUTO BRASILEIRO DE GEOGRAFIA E ESTATISTICA. Cidades. Rio de Janeiro 2017. Disponível em: https://cidades.ibge.gov.br/v4. Acesso em: 6 jul. 2018.

KUMAR, K. Da sociedade pós-industrial à pós-moderna. Rio de Janeiro: J. Zahar, 1997

LIBERATORE, M. J.; LUO, W. The analytics movement: implications for operations research. Interfaces, v. 40, p. 313-324, 2010.

LAUDON,C.K.; LAUDON, P. J. Sistemas de informação gerenciais: administrando a empresa digital. 7. ed. São Paulo: Prentice Hall, 2007.

LAKATOS, E. M.; MARCONI, M. A. Fundamentos de metodologia científica. 7. ed.São Paulo: Atlas, 2010. 298 p.

Leme, M. I. S. Resolução de conflitos interpessoais: interações entre cognição e afetividade na cultura. Porto Alegre. Psicologia reflexão e crítica, [S. I.], v. 17, n. 3, p. 367-380, 2004. 
O’BRIEN, J. A. Sistemas de informação: e as decisões gerenciais na era da Internet. 2. ed. São Paulo: Saraiva, 2004.

PEREIRA. C. P. A atividade de inteligência como instrumento de eficiência no exercício do controle externo pelo tribunal de contas da união. Belo Horizonte Centro Universitário Newton Paiva Escola Superior do Ministério Público de Minas Gerais 2009. In: ALMEIDA NETO, W. R. Inteligência e contra-inteligência no Ministério Público. Belo Horizonte: Dictum, 2009.

PORTAL CORPORATIVO. Disponível em: http:// www.policiamilitar.mg.gov.br. Acesso no dia: 28/08/2017.

SIEDSCHLAG, R. G.; CRUZ, T. M. F. O papel da atividade de inteligência de segurança pública no monitoramento dos movimentos sociais para a preservação da ordem pública. Revista Ordem Pública, 2014 v. 7, n. 1, p. 201-220, 2014. Disponível em:

https://rop.emnuvens.com.br/rop/article/view/74/73. Acesso em: 6 jul. 2018.

TURBAN, E. et al. Business intelligence - Um Enfoque Gerencial para a Inteligência do Negócio. Bookman, 2009.

ZARANTONELI, J, R. G. A atividade de inteligência como suporte às ações e operações de polícia ostensiva de preservação da ordem pública em Belo Horizonte. Belo Horizonte, Fundação João Pinheiro, 2002. 